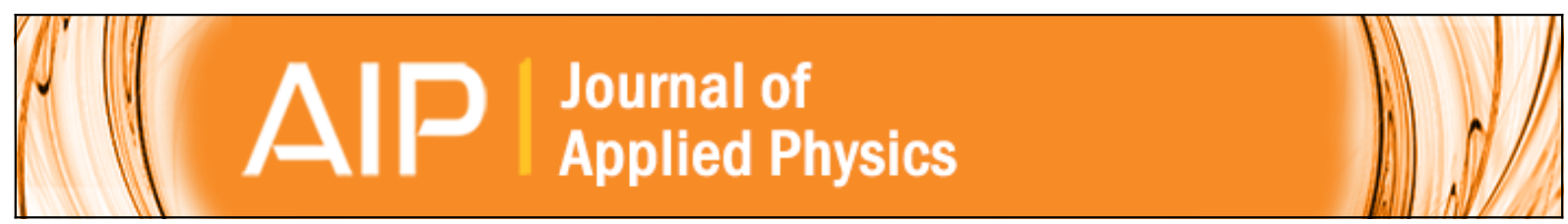

\title{
Direct and indirect capture of carriers into the lasing ground state and the light-current characteristic of quantum dot lasers
}

Yuchang Wu and Levon V. Asryan

Citation: Journal of Applied Physics 115, 103105 (2014); doi: 10.1063/1.4868472

View online: http://dx.doi.org/10.1063/1.4868472

View Table of Contents: http://scitation.aip.org/content/aip/journal/jap/115/10?ver=pdfcov

Published by the AIP Publishing

\section{Articles you may be interested in}

Effect of excited states on the ground-state modulation bandwidth in quantum dot lasers

Appl. Phys. Lett. 102, 191102 (2013); 10.1063/1.4804994

Ground-state power quenching in two-state lasing quantum dot lasers

J. Appl. Phys. 111, 043108 (2012); 10.1063/1.3682574

Thermally dependent characteristics and spectral hole burning of the double-lasing, edge-emitting quantum-dot laser

J. Appl. Phys. 107, 073104 (2010); 10.1063/1.3361376

Lasing characteristics of InAs quantum-dot lasers on (001) InP substrate

Appl. Phys. Lett. 83, 1704 (2003); 10.1063/1.1606501

Simultaneous two-state lasing in quantum-dot lasers

Appl. Phys. Lett. 82, 1818 (2003); 10.1063/1.1563742

MIT LINCOLN

LABORATORY CAREERS

Discover the satisfaction of innovation and service

to the nation
- Space Control

- Air \& Missile Defense

- Communications Systems \& Cyber Security

- Intelligence, Surveillance and

Reconnaissance Systems

- Advanced
Electronics
- Tactical Systems
- Homeland
Protection
- Air Traffic Control

LINCOLN LABORATORY

MassachusetTs Institute of TeChNOLOgY

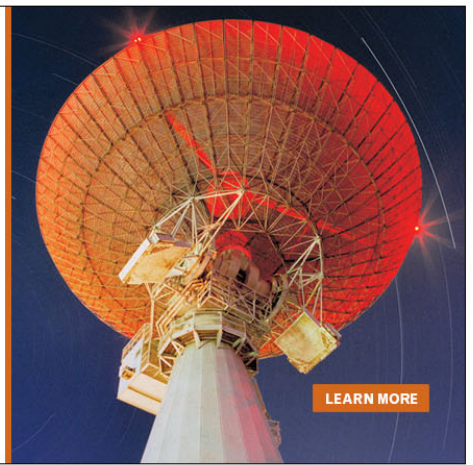




\title{
Direct and indirect capture of carriers into the lasing ground state and the light-current characteristic of quantum dot lasers
}

\author{
Yuchang $\mathrm{Wu}^{\mathrm{a})}$ and Levon V. Asryan ${ }^{\mathrm{b})}$ \\ Virginia Polytechnic Institute and State University, Blacksburg, Virginia 24061, USA
}

(Received 18 January 2014; accepted 3 March 2014; published online 13 March 2014)

\begin{abstract}
We calculate the light-current characteristic (LCC) of a quantum dot (QD) laser under the conditions of both direct and indirect capture of carriers from the optical confinement layer into the lasing ground state in QDs. We show that direct capture is a dominant process determining the ground-state LCC. Only when direct capture is slow, the role of indirect capture (capture into the QD excited state and subsequent intradot relaxation to the ground state) becomes important. (C) 2014 AIP Publishing LLC. [http://dx.doi.org/10.1063/1.4868472]
\end{abstract}

\section{INTRODUCTION}

Excited states in quantum dots (QDs) strongly affect the operation of QD lasers. ${ }^{1-18}$ In Refs. 19-21, the lightcurrent characteristic (LCC) of semiconductor lasers (the optical power as a function of the pump current) was calculated considering only direct capture of carriers from the optical confinement layer (OCL) into the lasing state in a quantum-confined active region. In Ref. 9, the LCC of a QD laser was studied assuming only an indirect (excited-statemediated) mechanism of capture into the QD ground state. In this work, we calculate the LCC of a QD laser under realistic conditions of both direct and indirect capture into the lasing ground state in QDs. We focus here on the effects of carrier exchange between a bulk OCL and zero-dimensional QDs and intradot relaxation. We show that, while indirect capture (capture into the QD excited state and subsequent intradot relaxation to the ground state) plays a part in determining the ground-state LCC, the role of direct capture is dominant.

\section{RATE EQUATIONS MODEL}

We use the following set of steady-state rate equations: for free carriers in the OCL $\left(\partial n_{\mathrm{OCL}} / \partial t=0\right)$,

$$
\begin{aligned}
& \frac{j}{e b}-\sigma_{\mathrm{n} 2} \mathrm{v}_{\mathrm{n}} \frac{N_{\mathrm{S}}}{b}\left(1-f_{\mathrm{n} 2}\right) n_{\mathrm{OCL}}+\sigma_{\mathrm{n} 2} \mathrm{v}_{\mathrm{n}} n_{2} \frac{N_{\mathrm{S}}}{b} f_{\mathrm{n} 2} \\
& \quad-\sigma_{\mathrm{n} 1} \mathrm{v}_{\mathrm{n}} \frac{N_{\mathrm{S}}}{b}\left(1-f_{\mathrm{n} 1}\right) n_{\mathrm{OCL}}+\sigma_{\mathrm{n} 1} \mathrm{v}_{\mathrm{n}} n_{1} \frac{N_{\mathrm{S}}}{b} f_{\mathrm{n} 1}-B n_{\mathrm{OCL}}^{2}=0,
\end{aligned}
$$

for carriers confined in the QD excited state $\left[2\left(N_{\mathrm{S}} / b\right) \partial f_{\mathrm{n} 2} / \partial t=0\right]$,

$$
\begin{aligned}
& \sigma_{\mathrm{n} 2} \mathrm{~V}_{\mathrm{n}} \frac{N_{\mathrm{S}}}{b}\left(1-f_{\mathrm{n} 2}\right) n_{\mathrm{OCL}}-\sigma_{\mathrm{n} 2} \mathrm{~V}_{\mathrm{n}} n_{2} \frac{N_{\mathrm{S}}}{b} f_{\mathrm{n} 2} \\
& +\frac{N_{\mathrm{S}}}{b} \frac{f_{\mathrm{n} 1}\left(1-f_{\mathrm{n} 2}\right)}{\tau_{12}}-\frac{N_{\mathrm{S}}}{b} \frac{f_{\mathrm{n} 2}\left(1-f_{\mathrm{n} 1}\right)}{\tau_{21}}-\frac{N_{\mathrm{S}}}{b} \frac{f_{\mathrm{n} 2}^{2}}{\tau_{\mathrm{QD} 2}}=0,
\end{aligned}
$$

\footnotetext{
a)Electronic mail: yuchangw@vt.edu

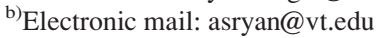

for carriers confined in the QD ground state $\left[2\left(N_{\mathrm{S}} / b\right) \partial f_{\mathrm{n} 1} / \partial t=0\right]$

$$
\begin{gathered}
\sigma_{\mathrm{n} 1} \mathrm{v}_{\mathrm{n}} \frac{N_{\mathrm{S}}}{b}\left(1-f_{\mathrm{n} 1}\right) n_{\mathrm{OCL}}-\sigma_{\mathrm{n} 1} \mathrm{v}_{\mathrm{n}} n_{1} \frac{N_{\mathrm{S}}}{b} f_{\mathrm{n} 1}+\frac{N_{\mathrm{S}}}{b} \frac{f_{\mathrm{n} 2}\left(1-f_{\mathrm{n} 1}\right)}{\tau_{21}} \\
-\frac{N_{\mathrm{S}}}{b} \frac{f_{\mathrm{n} 1}\left(1-f_{\mathrm{n} 2}\right)}{\tau_{12}}-\frac{N_{\mathrm{S}}}{b} \frac{f_{\mathrm{n} 1}^{2}}{\tau_{\mathrm{QD} 1}}-\mathrm{v}_{\mathrm{g}} g_{1}^{\max }\left(2 f_{\mathrm{n} 1}-1\right) \frac{N_{1}}{S b}=0,
\end{gathered}
$$

and for photons $\left(\partial N_{1} / \partial t=0\right)$,

$$
\mathrm{v}_{\mathrm{g}} g_{1}^{\max }\left(2 f_{\mathrm{n} 1}-1\right) N_{1}-\mathrm{v}_{\mathrm{g}} \beta N_{1}=0,
$$

where $n_{\mathrm{OCL}}$ is the free-carrier density in the OCL, $f_{\mathrm{n} 1}$ and $f_{\mathrm{n} 2}$ are the occupancies of the ground and excited state in a QD, and $N_{1}$ is the number of photons in the ground-state lasing mode.

The parameters in Eqs. (1)-(4) are as follows: $j$ is the injection current density, $e$ is the electron charge, $b$ is the OCL thickness, $v_{n}$ is the free-carrier thermal velocity in the OCL, $N_{\mathrm{S}}$ is the surface density of QDs, $B$ is the spontaneous radiative recombination constant for the OCL, $\tau_{\mathrm{QD} 1}$ and $\tau_{\mathrm{QD} 2}$ are the spontaneous radiative recombination lifetimes via the QD ground and excited state, $S=W L$ is the cross section of the junction, $W$ is the lateral size of the device, and $L$ is the cavity length.

To adequately describe the carrier exchange between the OCL and QDs, we use the cross-sections $\sigma_{\mathrm{n} 1}$ and $\sigma_{\mathrm{n} 2}$ of carrier capture from the OCL into the QD ground and excited state.

The quantities $n_{1}$ and $n_{2}$ entering into the rates of thermal escape of carriers from the QD ground and excited state to the OCL [see Eqs. (1)-(3)] are given by $n_{1}=$ $N_{\mathrm{c}}^{3 \mathrm{D}} \exp \left(-E_{\mathrm{n} 1} / T\right)$ and $n_{2}=N_{\mathrm{c}}^{3 \mathrm{D}} \exp \left(-E_{\mathrm{n} 2} / T\right)$, where $E_{\mathrm{n} 1}$ and $E_{\mathrm{n} 2}$ are the energies of carrier excitation from the QD ground and excited state to the OCL (Fig. 1), and $T$ is the temperature (in units of energy).

In Eqs. (2) and (3), $\tau_{12}$ is the upward (ground-to-excited state) transition time and $\tau_{21}$ is the excited-to-ground state relaxation time in a QD. The detailed balance condition yields the following relationship between these intradot times: 


$$
\tau_{12}=\tau_{21} \exp \left(\frac{E_{\mathrm{n} 1}-E_{\mathrm{n} 2}}{T}\right) .
$$

In Eqs. (3) and (4), $\mathrm{v}_{\mathrm{g}}$ is the group velocity of light, $g_{1}^{\max }$ is the maximum modal gain of ground-state lasing, ${ }^{22}$ $\beta=(1 / L) \ln (1 / R)$ is the mirror loss, and $R$ is the facet reflectivity.

We use quadratic (in free-carrier density $n_{\mathrm{OCL}}$ and confined-carrier level occupancies $f_{\mathrm{n} 1}$ and $f_{\mathrm{n} 2}$ ) rates [the last terms in the left-hand sides of Eqs. (1) and (2) and the fifth term in the left-hand side of Eq. (3)] for spontaneous radiative recombination in the OCL and QDs, since this process is bimolecular. ${ }^{22}$

We focus here on the effects of carrier capture into QDs and intradot relaxation on the lower- (ground-) state lasing, and, for this reason, we do not consider the stimulated emission via the upper (excited) state in QDs. To rule out the stimulated emission via the excited state in QDs, we set the maximum modal gain via excited-state transitions lower than the mirror loss $\beta$. Correspondingly, our model does not incorporate the onset of excited-state lasing with increasing pump current, simultaneous two (or even more) state lasing, or quenching of ground-state lasing-see, e.g., Refs. 1-8 and Refs. 10-18 for discussion of these and other interesting phenomena occuring due to the presence of excited states in QDs.

Our model does not also include the electron-hole asymmetry. Consideration of the electron-hole asymmetry would involve at least seven rate equations instead of four equations (1)-(4).

Solving the set of rate equations (1)-(4) and finding the number of photons $N_{1}$ in the lasing mode will give us the output optical power of the laser,

$$
P=\hbar \omega \mathrm{v}_{\mathrm{g}} \beta N_{1}=\hbar \omega \frac{N_{1}}{\tau_{\mathrm{ph}}},
$$

where $\hbar \omega$ is the energy of photons emitted via the groundstate transitions and we introduced the photon lifetime in the cavity,

$$
\tau_{\mathrm{ph}}=\frac{1}{\mathrm{v}_{\mathrm{g}} \beta} .
$$

\section{SOLUTIONS OF RATE EQUATIONS}

As seen from Eq. (4), for the number of photons to be nonzero $\left(N_{1} \neq 0\right)$, the condition of equality of the gain to the loss should hold

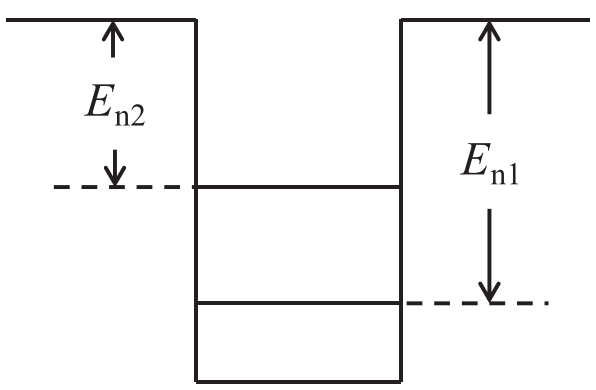

FIG. 1. Carrier excitation energies $E_{\mathrm{n} 1}$ and $E_{\mathrm{n} 2}$ from the QD ground and excited state to the OCL. For the QD laser structures considered in this paper, $E_{\mathrm{n} 1}=49 \mathrm{meV}$ and $E_{\mathrm{n} 2}=23 \mathrm{meV}$.

$$
g_{1}^{\max }\left(2 f_{\mathrm{n} 1}-1\right)=\beta
$$

which immediately yields the following expression for the ground-state level occupancy in QDs:

$$
f_{\mathrm{n} 1}=\frac{1}{2}\left(1+\frac{\beta}{g_{1}^{\max }}\right) .
$$

As seen from Eq. (9), $f_{\mathrm{n} 1}$ does not depend on $j$, i.e., is pinned at its threshold value. In contrast to $f_{\mathrm{n} 1}$, as shown below [Figs. 2(a) and 2(b)], the excited-state level occupancy
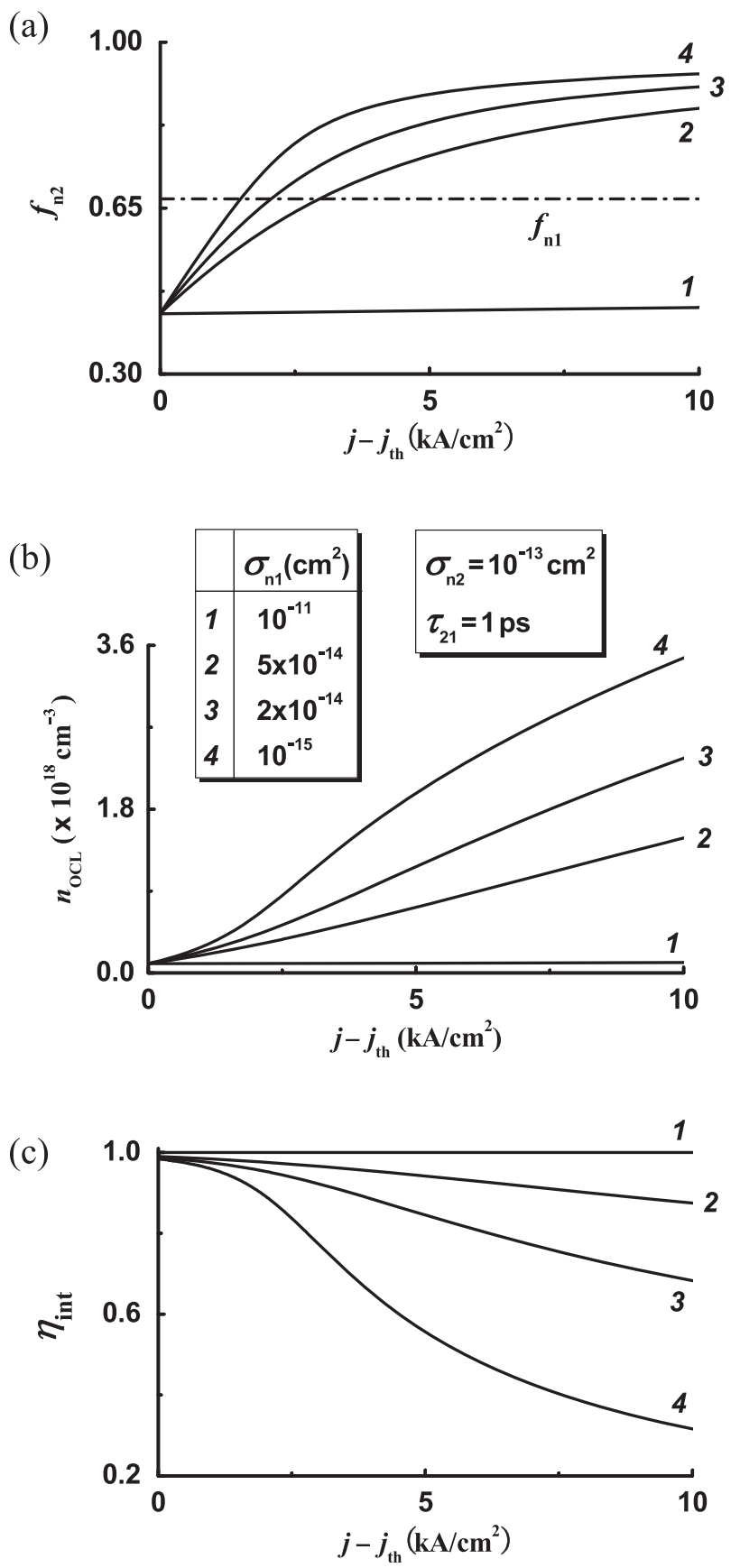

FIG. 2. Excited-state level occupancy in QDs (a), free-carrier density in the OCL (b), and internal differential quantum efficiency (c) vs. excess of the injection current density over the threshold current density for different values of the capture cross-section $\sigma_{\mathrm{n} 1}$ into the QD ground state. The horizontal dashed-dotted line in (a) shows the ground-state level occupancy. The values of parameters $\sigma_{\mathrm{n} 1}, \sigma_{\mathrm{n} 2}$, and $\tau_{21}$ are indicated in the inset to (b). 
in QDs, $f_{\mathrm{n} 2}$, and the free-carrier density in the OCL, $n_{\mathrm{OCL}}$, increase with $j$ above the lasing threshold.

We use the following approach to solving the rate equations: we express $n_{\mathrm{OCL}}$ and the number of photons $N_{1}$ in terms of $f_{\mathrm{n} 2}$, and then obtain a single equation for finding $f_{\mathrm{n} 2}$ [Eq. (13) below].

From Eq. (2), the free-carrier density in the OCL can be written as follows in terms of $f_{\mathrm{n} 2}$ :

$$
\begin{aligned}
n_{\mathrm{OCL}}\left(f_{\mathrm{n} 2}\right)= & n_{2} \frac{f_{\mathrm{n} 2}}{1-f_{\mathrm{n} 2}}+\frac{1}{\sigma_{\mathrm{n} 2} \mathrm{v}_{\mathrm{n}}} \frac{1}{1-f_{\mathrm{n} 2}} \\
& \times\left[\frac{f_{\mathrm{n} 2}\left(1-f_{\mathrm{n} 1}\right)}{\tau_{21}}-\frac{f_{\mathrm{n} 1}\left(1-f_{\mathrm{n} 2}\right)}{\tau_{12}}+\frac{f_{\mathrm{n} 2}^{2}}{\tau_{\mathrm{QD} 2}}\right] .
\end{aligned}
$$

From Eq. (3), we have for the number of photons

$$
\begin{aligned}
N_{1}\left(f_{\mathrm{n} 2}\right)= & {\left[\tau_{\mathrm{ph}} N_{\mathrm{S}} S \sigma_{\mathrm{n} 1} \mathrm{v}_{\mathrm{n}}\left(1-f_{\mathrm{n} 1}\right) n_{\mathrm{OCL}}\left(f_{\mathrm{n} 2}\right)-\sigma_{\mathrm{n} 1} \mathrm{v}_{\mathrm{n}} n_{1} f_{\mathrm{n} 1}\right.} \\
& \left.+\frac{f_{\mathrm{n} 2}\left(1-f_{\mathrm{n} 1}\right)}{\tau_{21}}-\frac{f_{\mathrm{n} 1}\left(1-f_{\mathrm{n} 2,}\right)}{\tau_{12}}-\frac{f_{\mathrm{n} 1}^{2}}{\tau_{\mathrm{QD} 1}}\right] .
\end{aligned}
$$

An expression for $N_{1}$ equivalent to Eq. (11) can also be obtained by adding Eqs. (2) and (3)

$$
\begin{aligned}
N_{1}\left(f_{\mathrm{n} 2}\right)= & \tau_{\mathrm{ph}} N_{\mathrm{S}} S\left\{\left[\sigma_{\mathrm{n} 1} \mathrm{v}_{\mathrm{n}}\left(1-f_{\mathrm{n} 1}\right) n_{\mathrm{OCL}}\left(f_{\mathrm{n} 2}\right)-\sigma_{\mathrm{n} 1} \mathrm{v}_{\mathrm{n}} n_{1} f_{\mathrm{n} 1}\right]\right. \\
& +\left[\sigma_{\mathrm{n} 2} \mathrm{v}_{\mathrm{n}}\left(1-f_{\mathrm{n} 2}\right) n_{\mathrm{OCL}}\left(f_{\mathrm{n} 2}\right)-\sigma_{\mathrm{n} 2} \mathrm{v}_{\mathrm{n}} n_{2} f_{\mathrm{n} 2}\right] \\
& \left.-\frac{f_{\mathrm{n} 1}^{2}}{\tau_{\mathrm{QD} 1}}-\frac{f_{\mathrm{n} 2}^{2}}{\tau_{\mathrm{QD} 2}}\right\} .
\end{aligned}
$$

Adding equations (1), (2), and (3), we can naturally express the injection current density as a sum of the current densities of spontaneous recombination in the OCL and in QDs (the first three terms in the right-hand side below) and stimulated recombination in QDs (the last term)

$$
j=e b B n_{\mathrm{OCL}}^{2}\left(f_{\mathrm{n} 2}\right)+e N_{\mathrm{S}} \frac{f_{\mathrm{n} 1}^{2}}{\tau_{\mathrm{QD} 1}}+e N_{\mathrm{S}} \frac{f_{\mathrm{n} 2}^{2}}{\tau_{\mathrm{QD} 2}}+\frac{e}{S} \frac{N_{1}\left(f_{\mathrm{n} 2}\right)}{\tau_{\mathrm{ph}}} .
$$

Equation (13) [wherein $n_{\mathrm{OCL}}\left(f_{\mathrm{n} 2}\right)$ and $N_{1}\left(f_{\mathrm{n} 2}\right)$ are given by Eqs. (10) and (11), respectively] presents the injection current density $j$ as an explicit function of the excited-state level occupancy in QDs $f_{\mathrm{n} 2}$. We need to find the inverse function, i.e., $f_{\mathrm{n} 2}$ versus $j$. In terms of $f_{\mathrm{n} 2}$, Eq. (13) can be presented as a quartic equation. Solving this equation, we obtain $f_{\mathrm{n} 2}(j)$; then, using Eqs. (10) and (11), we calculate $n_{\mathrm{OCL}}(j)$ and $N_{1}(j)$, and finally $P(j)$ [see Eq. (6)].

Equation (13) can also be written as

$$
j=j_{\text {th }}+\Delta j_{\text {spon }}(j)+j_{\text {stim }}(j),
$$

where

$$
j_{\mathrm{th}}=e N_{\mathrm{S}} \frac{f_{\mathrm{n} 1}^{2}}{\tau_{\mathrm{QD} 1}}+e N_{\mathrm{S}} \frac{f_{\mathrm{n} 2, \mathrm{th}}^{2}}{\tau_{\mathrm{QD} 2}}+e b B n_{\mathrm{OCL}, \mathrm{th}}^{2}
$$

is the threshold current density (see Appendix for the expressions for the free-carrier density in the OCL $n_{\mathrm{OCL}}$, th and the excited-state level occupancy in QDs $f_{\mathrm{n} 2 \text {, th }}$ at the lasing threshold),

$$
\Delta j_{\mathrm{spon}}(j)=\frac{e N_{\mathrm{S}}}{\tau_{\mathrm{QD} 2}}\left[f_{\mathrm{n} 2}^{2}(j)-f_{\mathrm{n} 2, \mathrm{th}}^{2}\right]+e b B\left[n_{\mathrm{OCL}}^{2}(j)-n_{\mathrm{OCL}, \mathrm{th}}^{2}\right]
$$

is the raise in the spontaneous radiative recombination current density above the lasing threshold, and

$$
j_{\mathrm{stim}}(j)=\frac{e}{S} \frac{N_{1}(j)}{\tau_{\mathrm{ph}}}
$$

is the stimulated recombination current density.

For the internal differential quantum efficiency (efficiency of stimulated recombination), ${ }^{23}$ we have

$$
\begin{aligned}
\eta_{\mathrm{int}}(j) & =\frac{j_{\mathrm{stim}}(j)}{j-j_{\mathrm{th}}}=1-\frac{\Delta j_{\mathrm{spon}}(j)}{j-j_{\mathrm{th}}} \\
& =1-\frac{\frac{e N_{\mathrm{S}}}{\tau_{\mathrm{QD} 2}}\left[f_{\mathrm{n} 2}^{2}(j)-f_{\mathrm{n} 2, \mathrm{th}}^{2}\right]+e b B\left[n_{\mathrm{OCL}}^{2}(j)-n_{\mathrm{OCL}, \mathrm{th}}^{2}\right]}{j-j_{\mathrm{th}}} .
\end{aligned}
$$

\section{DISCUSSION}

For our calculations, we use a GaInAsP heterostructure operating at room-temperature. ${ }^{24,25}$ The lasing wavelength is near $1.55 \mu \mathrm{m}$. The maximum gain for the ground-state transitions $g_{1}^{\max }=29.52 \mathrm{~cm}^{-1}$, which corresponds to $10 \%$ QD-size fluctuations and surface density of QDs $N_{\mathrm{S}}=6.11$ $\times 10^{10} \mathrm{~cm}^{-2}$. We assume the mirror loss $\beta=10 \mathrm{~cm}^{-1}$ (for as-cleaved facet reflectivity $R=0.32$, this corresponds to the cavity length $L=1.139 \mathrm{~mm}$ ). The OCL thickness $b=0.28 \mu \mathrm{m}$ and the lateral size $W=2 \mu \mathrm{m}$.

Figures 2(a) and 2(b) show the excited-state level occupancy in QDs and the free-carrier density in the OCL against excess of the injection current density over the threshold current density. As seen from the figures, carriers accumulate in non-lasing states in the OCL and QDs above the lasing threshold-both $f_{\mathrm{n} 2}$ and $n_{\mathrm{OCL}}$ raise with $j$. The accumulation is due to delay in carrier delivery (capture and intradot relaxation) from these non-lasing states into the lasing state in QDs. When the capture into the QD ground state is very fast (curve 1 in the figures), $f_{\mathrm{n} 2}$ and $n_{\mathrm{OCL}}$ are practically constant.

Figure 2(c) shows the internal differential quantum efficiency against excess injection current density for different values of the capture cross-section $\sigma_{\mathrm{n} 1}$ into the QD ground state. As seen from the figure, $\eta_{\text {int }}$ decreases with increasing $j$. As clear from Eq. (18), this decrease is related to a raise $\Delta j_{\text {spon }}$ in the spontaneous radiative recombination current density above the lasing threshold caused in turn by a raise in $f_{\mathrm{n} 2}$ and $n_{\mathrm{OCL}}$. With making faster the direct capture (increasing $\sigma_{\mathrm{n} 1}$ ), fewer carriers are accumulated in non-lasing states thus reducing $\Delta j_{\text {spon }}$ and enhancing $\eta_{\text {int }}$. At very fast direct capture [curve 1 in Fig. 2(c)], $\eta_{\text {int }}$ is almost unchanged with increasing $j$.

The output optical power vs. excess of the injection current density $j$ over the threshold current density $j_{\text {th }}$ is 
shown in Fig. 3 for wide ranges of parameters $\sigma_{\mathrm{n} 1}, \sigma_{\mathrm{n} 2}$, and $\tau_{21}$. In Fig. 3(a), $\sigma_{\mathrm{n} 1}$ is different for different curves, while $\sigma_{\mathrm{n} 2}$ and $\tau_{21}$ are fixed. In Fig. 3(b), $\sigma_{\mathrm{n} 2}$ is different for different curves, while $\sigma_{\mathrm{n} 1}$ and $\tau_{21}$ are fixed. In Fig. 3(c), $\tau_{21}$ is
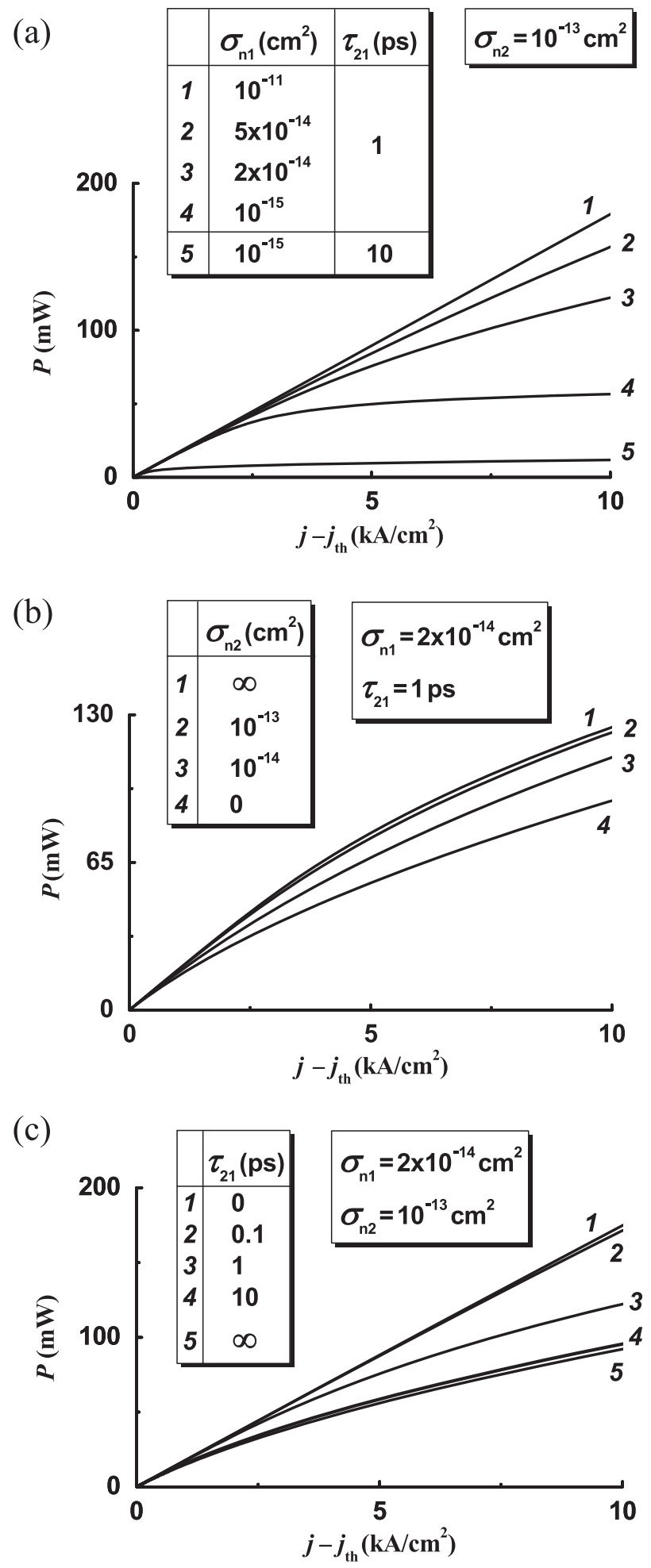

FIG. 3. Light-current characteristic of a QD laser. The abscissa shows the excess of the injection current density over the threshold current densitythat is why all the curves start from the origin. In (a), $\sigma_{\mathrm{n} 1}$ is different for different curves, while $\sigma_{\mathrm{n} 2}$ and $\tau_{21}$ are fixed. In (b), $\sigma_{\mathrm{n} 2}$ is different for different curves, while $\sigma_{\mathrm{n} 1}$ and $\tau_{21}$ are fixed. In (c), $\tau_{21}$ is different for different curves, while $\sigma_{\mathrm{n} 1}$ and $\sigma_{\mathrm{n} 2}$ are fixed. The values of parameters $\sigma_{\mathrm{n} 1}, \sigma_{\mathrm{n} 2}$, and $\tau_{21}$ are indicated in the corresponding insets. different for different curves, while $\sigma_{\mathrm{n} 1}$ and $\sigma_{\mathrm{n} 2}$ are fixed. With increasing either $\sigma_{\mathrm{n} 1}$ or $\sigma_{\mathrm{n} 2}$ and with decreasing $\tau_{21}$, the LCC becomes more linear and the output power becomes higher at the same value of $j-j_{\text {th }}$. As seen from Fig. 3(a), the effect of direct capture (capture into the QD ground state) on the LCC is strong. The role of indirect capture (capture into the QD excited state and subsequent intradot relaxation), as seen from Figs. 3(b) and 3(c), becomes important only when direct capture is slow. In order to show a noticeable change in the LCC in Figs. 3(b) and 3(c), we used a small $\sigma_{\mathrm{n} 1}$ and varied $\sigma_{\mathrm{n} 2}$ and $\tau_{21}$ within entire ranges of their possible values $\left[\sigma_{\mathrm{n} 2}\right.$ - from infinity (instantaneous capture into the excited state) to zero (no capture into the excited state), $\tau_{21}$-from zero (instantaneous intradot relaxation) to infinity (no intradot relaxation)].

\section{CONCLUSIONS}

We have calculated the LCC of a QD laser under the conditions of both direct and indirect capture of carriers from the OCL into the lasing ground state in QDs. We have shown that direct capture is a dominant process determining the groundstate LCC. Only when direct capture is slow, the role of indirect capture (capture into the excited state and subsequent intradot relaxation to the ground state) becomes important.

\section{ACKNOWLEDGMENTS}

This work was supported by the U.S. Army Research Office (Grant No. W911NF-13-1-0445).

\section{APPENDIX: EXCITED-STATE LEVEL OCCUPANCY IN QDS AND FREE-CARRIER DENSITY IN THE OCL AT THE LASING THRESHOLD}

At the lasing threshold, the number of photons $N_{1}=0$. The free-carrier density in the OCL at the lasing threshold can be obtained from either of equations (10), (11), or (12). Correspondingly, we have the following three equivalent expressions for $n_{\mathrm{OCL}, \text { th }}$ :

$$
\begin{aligned}
& n_{\mathrm{OCL}, \mathrm{th}}=n_{2} \frac{f_{\mathrm{n} 2, \mathrm{th}}}{1-f_{\mathrm{n} 2, \mathrm{th}}}+\frac{1}{\sigma_{\mathrm{n} 2 \mathrm{v}_{\mathrm{n}}}} \frac{1}{1-f_{\mathrm{n} 2, \mathrm{th}}} \\
& \times\left[\frac{f_{\mathrm{n} 2, \mathrm{th}}\left(1-f_{\mathrm{n} 1}\right)}{\tau_{21}}-\frac{f_{\mathrm{n} 1}\left(1-f_{\mathrm{n} 2, \mathrm{th}}\right)}{\tau_{12}}+\frac{f_{\mathrm{n} 2, \mathrm{th}}^{2}}{\tau_{\mathrm{QD} 2}}\right] \text {, } \\
& n_{\mathrm{OCL}, \mathrm{th}}=n_{1} \frac{f_{\mathrm{n} 1}}{1-f_{\mathrm{n} 1}}+\frac{1}{\sigma_{\mathrm{n} 1} \mathrm{v}_{\mathrm{n}}\left(1-f_{\mathrm{n} 1}\right)} \\
& \times\left[\frac{f_{\mathrm{n} 1}\left(1-f_{\mathrm{n} 2, \mathrm{th}}\right)}{\tau_{12}}-\frac{f_{\mathrm{n} 2, \mathrm{th}}\left(1-f_{\mathrm{n} 1}\right)}{\tau_{21}}+\frac{f_{\mathrm{n} 1}^{2}}{\tau_{\mathrm{QD} 1}}\right] \text {, } \\
& n_{\mathrm{OCL}, \mathrm{th}}=\frac{\sigma_{\mathrm{n} 1} \mathrm{v}_{\mathrm{n}} n_{1} f_{\mathrm{n} 1}+\sigma_{\mathrm{n} 2} \mathrm{v}_{\mathrm{n}} n_{2} f_{\mathrm{n} 2, \mathrm{th}}+\frac{f_{\mathrm{n} 1}^{2}}{\tau_{\mathrm{QD} 1}}+\frac{f_{\mathrm{n} 2, \mathrm{th}}^{2}}{\tau_{\mathrm{QD} 2}}}{\sigma_{\mathrm{n} 1} \mathrm{v}_{\mathrm{n}}\left(1-f_{\mathrm{n} 1}\right)+\sigma_{\mathrm{n} 2} \mathrm{v}_{\mathrm{n}}\left(1-f_{\mathrm{n} 2, \mathrm{th}}\right)} .
\end{aligned}
$$

Equalizing (A1) and (A2), we obtain the following quadratic equation in the excited-state level occupancy $f_{\mathrm{n} 2 \text {, th }}$ in QDs at the lasing threshold: 


$$
\begin{aligned}
& {\left[\left(\frac{f_{\mathrm{n} 1}}{1-f_{\mathrm{n} 1}} \frac{1}{\tau_{12}}+\frac{1}{\tau_{21}}\right) \sigma_{\mathrm{n} 2}-\frac{1}{\tau_{\mathrm{QD} 2}} \sigma_{\mathrm{n} 1}\right] f_{\mathrm{n} 2, \mathrm{th}}^{2}-\left[\sigma_{\mathrm{n} 1} \sigma_{\mathrm{n} 2} \mathrm{v}_{\mathrm{n}}\left(n_{1} \frac{f_{\mathrm{n} 1}}{1-f_{\mathrm{n} 1}}+n_{2}\right)+\left(\frac{f_{\mathrm{n} 1}^{2}}{1-f_{\mathrm{n} 1}} \frac{1}{\tau_{\mathrm{QD} 1}}+\frac{2 f_{\mathrm{n} 1}}{1-f_{\mathrm{n} 1}} \frac{1}{\tau_{12}}+\frac{1}{\tau_{21}}\right) \sigma_{\mathrm{n} 2}\right.} \\
& \left.\quad+\left(\frac{f_{\mathrm{n} 1}}{\tau_{12}}+\frac{1-f_{\mathrm{n} 1}}{\tau_{21}}\right) \sigma_{\mathrm{n} 1}\right] f_{\mathrm{n} 2, \mathrm{th}}+\left[\sigma_{\mathrm{n} 1} \sigma_{\mathrm{n} 2 \mathrm{v}_{\mathrm{n}}} n_{1} \frac{f_{\mathrm{n} 1}}{1-f_{\mathrm{n} 1}}+\left(\frac{f_{\mathrm{n} 1}^{2}}{1-f_{\mathrm{n} 1}} \frac{1}{\tau_{\mathrm{QD} 1}}+\frac{f_{\mathrm{n} 1}}{1-f_{\mathrm{n} 1}} \frac{1}{\tau_{12}}\right) \sigma_{\mathrm{n} 2}+\frac{f_{\mathrm{n} 1}}{\tau_{12}} \sigma_{\mathrm{n} 1}\right]=0 .
\end{aligned}
$$

Only one of the roots of Eq. (A4) is real, positive, and smaller than unity, and hence is physical.

With the solution of Eq. (A4) for $f_{\mathrm{n} 2 \text {, th }}$ and either of expressions (A1), (A2), or (A3) for $n_{\mathrm{OCL}}$, th, we calculate the threshold current density [see Eq. (15)].

If the carrier capture/escape into/from a QD is excitedstate-mediated only (i.e., $\sigma_{\mathrm{n} 1}=0$ ), the expression for $f_{\mathrm{n} 2 \text {, th }}$ considerably simplifies

$$
f_{\mathrm{n} 2, \mathrm{th}}=\frac{1}{\left(1-f_{\mathrm{n} 1}\right) \frac{\tau_{12}}{\tau_{21}}+f_{\mathrm{n} 1}}\left(f_{\mathrm{n} 1}+\frac{\tau_{12}}{\tau_{\mathrm{QD} 1}} f_{\mathrm{n} 1}^{2}\right) .
$$

In this case, Eq. (A3) for $n_{\mathrm{OCL}}$, th becomes

$$
n_{\mathrm{OCL}, \mathrm{th}}=n_{2} \frac{f_{\mathrm{n} 2, \mathrm{th}}}{1-f_{\mathrm{n} 2, \mathrm{th}}}+\frac{1}{\sigma_{\mathrm{n} 2} \mathrm{v}_{\mathrm{n}}} \frac{1}{1-f_{\mathrm{n} 2, \mathrm{th}}}\left(\frac{f_{\mathrm{n} 1}^{2}}{\tau_{\mathrm{QD} 1}}+\frac{f_{\mathrm{n} 2, \mathrm{th}}^{2}}{\tau_{\mathrm{QD} 2}}\right) \text {. }
$$

${ }^{1}$ L. Harris, A. D. Ashmore, D. J. Mowbray, M. S. Skolnick, M. Hopkinson, G. Hill, and J. Clark, Appl. Phys. Lett. 75, 3512 (1999).

${ }^{2}$ P. Bhattacharya, D. Klotzkin, O. Qasaimeh, W. Zhou, S. Krishna, and D. Zhu, IEEE J. Sel. Top. Quantum Electron. 6, 426 (2000).

${ }^{3}$ L. V. Asryan, M. Grundmann, N. N. Ledentsov, O. Stier, R. A. Suris, and D. Bimberg, J. Appl. Phys. 90, 1666 (2001).

${ }^{4}$ P. Miska, C. Paranthoen, J. Even, O. Dehaese, H. Folliot, N. Bertru, S. Loualiche, M. Senes, and X. Marie, Semicond. Sci. Technol. 17, L63 (2002).

${ }^{5}$ A. Markus and A. Fiore, Phys. Status Solidi A 201, 338 (2004).

${ }^{6}$ M. Sugawara, N. Hatori, H. Ebe, M. Ishida, Y. Arakawa, T. Akiyama, K. Otsubo, and Y. Nakata, J. Appl. Phys. 97, 043523 (2005).
${ }^{7}$ A. Martinez, A. Lemaitre, K. Merghem, L. Ferlazzo, C. Dupuis, A. Ramdane, J. G. Provost, B. Dagens, O. Le Gouezigou, and O. GauthierLafaye, Appl. Phys. Lett. 86, 211115 (2005).

${ }^{8}$ E. A. Viktorov, P. Mandel, Y. Tanguy, J. Houlihan, and G. Huyet, Appl. Phys. Lett. 87, 053113 (2005).

${ }^{9}$ L. Jiang and L. V. Asryan, IEEE Photon. Technol. Lett. 18, 2611 (2006).

${ }^{10}$ K. Veselinov, F. Grillot, P. Miska, E. Homeyer, P. Caroff, C. Platz, J. Even, X. Marie, O. Dehaese, S. Loualiche, and A. Ramdane, Optic. Quantum Electron. 38, 369 (2006).

${ }^{11}$ K. Veselinov, F. Grillot, C. Cornet, J. Even, A. Bekiarski, M. Gioannini, and S. Loualiche, IEEE J. Quantum Electron. 43, 810 (2007).

${ }^{12}$ G. S. Sokolovskii, M. A. Cataluna, A. G. Deryagin, V. I. Kuchinskii, I. I. Novikov, M. V. Maksimov, A. E. Zhukov, V. M. Ustinov, W. Sibbett, and E. U. Rafailov, Tech. Phys. Lett. 33, 4 (2007).

${ }^{13}$ W. Rudno-Rudzinski, G. Sek, K. Ryczko, M. Syperek, J. Misiewicz, E. S. Semenova, A. Lemaitre, and A. Ramdane, Phys. Status Solidi A 206, 826 (2009).

${ }^{14}$ Z. Y. Zhang, Q. Jiang, and R. A. Hogg, Electron. Lett. 46, 1155 (2010).

${ }^{15}$ M. Gioannini, J. Appl. Phys. 111, 043108 (2012).

${ }^{16} \mathrm{~T}$. Xu, M. Rossetti, P. Bardella, and I. Montrosset, IEEE J. Quantum Electron. 48, 1193 (2012).

${ }^{17}$ V. V. Korenev, A. V. Savelyev, A. E. Zhukov, A. V. Omelchenko, and M. V. Maximov, Appl. Phys. Lett. 102, 112101 (2013).

${ }^{18}$ F. Grillot, C. Wang, N. A. Naderi, and J. Even, IEEE J. Sel. Top. Quantum Electron. 19, 1900812 (2013).

${ }^{19}$ L. V. Asryan, S. Luryi, and R. A. Suris, Appl. Phys. Lett. 81, 2154 (2002).

${ }^{20}$ L. V. Asryan, S. Luryi, and R. A. Suris, IEEE J. Quantum Electron. 39, 404 (2003).

${ }^{21}$ L. V. Asryan and Z. N. Sokolova, J. Appl. Phys. 115, 023107 (2014).

${ }^{22}$ L. V. Asryan and R. A. Suris, Semicond. Sci. Technol. 11, 554 (1996).

${ }^{23}$ L. A. Coldren and S. W. Corzine, Diode Lasers and Photonic Integrated Circuits (Wiley, New York, 1995).

${ }^{24}$ L. V. Asryan and R. A. Suris, Appl. Phys. Lett. 74, 1215 (1999).

${ }^{25}$ L. V. Asryan and S. Luryi, Appl. Phys. Lett. 83, 5368 (2003). 